\title{
Vidas e (re)existências no território quilombola da Costa da Lagoa
}

Lives and (re)existences in the quilombola territory of Costa da Lagoa

\section{Eleandra Raquel da Silva Koch e Vanessa Flores dos Santos}

\section{(2) OpenEdition}

12 Journals

Edição electrónica

URL: http://journals.openedition.org/aa/6606

DOI: $10.4000 / a a .6606$

ISSN: 2357-738X

Editora

Programa de Pós-Graduação em Antropologia Social (UnB)

\section{Edição impressa}

Paginação: 169-186

ISSN: 0102-4302

Refêrencia eletrónica

Eleandra Raquel da Silva Koch e Vanessa Flores dos Santos, «Vidas e (re)existências no território quilombola da Costa da Lagoa», Anuário Antropológico [Online], v.45 n.3 | 2020, posto online no dia 16 setembro 2020, consultado o 27 abril 2021. URL: http://journals.openedition.org/aa/6606 ; DOI: https://doi.org/10.4000/aa.6606

\section{(c) $(1)(9)$}

Anuário Antropológico is licensed under a Creative Commons Atribuição-Uso Não-Comercial-Proibição de realização de Obras Derivadas 4.0 International. 


\title{
Vidas e (re)existências no território quilombola da Costa da Lagoa
}

\author{
Lives and (re)existences in the quilombola territory of Costa da Lagoa \\ DOI: https://doi.org/10.4000/aa.6606
}

\begin{abstract}
Eleandra Raquel da Silva Koch
Universidade Federal do Rio Grande do Sul - Brasil

Instituto Nacional de Colonização e Reforma Agrária, Rio Grande do Sul - Brasil

Cientista social, mestra em Sociologia e doutoranda em Desenvolvimento Rural pela Universidade Federal do Rio Grande do Sul. Atua como analista em reforma e desenvolvimento agrário e antropologia no INCRA/RS.
\end{abstract}

ORCID: $\odot \odot \odot \odot-\odot \odot \odot 2-6882-5987$

eleandraraquelegmail.com

\begin{abstract}
Vanessa Flores dos Santos
Instituto Nacional de Colonização e Reforma Agrária, Rio Grande do Sul - Brasil

Cientista social pela Universidade Federal de Santa Maria e mestra em Antropologia Social pela Universidade Federal do Rio Grande do Sul. Atua como analista em reforma e desenvolvimento agrário e antropologia no INCRA/RS.
\end{abstract}

Este artigo analisa processos de luta por (re)existência em um território quilombola que se fundou às margens da Lagoa Capivari. Através de práticas de conhecimentos locais que remetem a importantes ciclos de vida da coletividade negra, como os batismos "em casa" e as festas de Nossa Senhora de Navegantes, evidenciam-se potentes relações que os quilombolas da Costa da Lagoa mobilizam com as águas e demais seres não-humanos, com os quais partilham de seu território ancestral. 0 trabalho etnográfico que nos oportunizou conhecer o quilombo da Costa da Lagoa e aprender sobre as dinâmicas abordadas neste trabalho foi elaborado no bojo do processo administrativo de regularização fundiária do território quilombola referido. Assim, os condicionantes de produção da pesquisa sob tal modalidade compõem a reflexão proposta. Observa-se, assim, que na força das águas e dos saberes passados pelos mais antigos, o grupo, em aliança com os não-humanos, vem fazendo frente a projetos e seus aparatos sociotécnicos manejados no intento de transformar o território ancestral em um lugar funcional ao "desenvolvimento" e ao lucro.

Comunidade Quilombola da Costa da Lagoa. Território negro. Águas. Existências. Desenvolvimento.
This article analyzes processes of struggle for (re)existence in a quilombola territory that was founded on the banks of Lagoa Capivari. Through local knowledge practices that refer to important life cycles of the black community, such as homemade baptisms and the feasts of Nossa Senhora de Navegantes, there are potent relationships that the quilombolas of Costa da Lagoa mobilize with the water and other non-humans entities, with whom they share their ancestral territory. The ethnographic work that made it possible for us to get to know the quilombo in Costa da Lagoa and learn about the dynamics covered in this work was elaborated amid the administrative process of land tenure regularization of the referred quilombola territory. Thus, the research production constraints under this modality give place to the proposed reflection. Therefore, it is observed that with the strength of the waters and the knowledge passed on by the elders, the group, in alliance with non-humans beings, has been resisting to projects and their socio-technical devices managed in an attempt to transform the ancestral territory into a functional place for "development" and profit.

Costa da Lagoa Quilombola Community. Black territory. Waters. Existences. Development. 


\section{Introdução}

Este artigo versa sobre práticas de (re)existência ${ }^{1}$ da coletividade que atualmente se reconhece enquanto a comunidade quilombola da Costa da Lagoa, situada na beira da Lagoa Capivari, no município de Capivari do Sul (Rio Grande do Sul). Segundo as narrativas locais, com base nas memórias coletivas familiares e comunitárias, desde a ocupação ancestral deste território as parentelas negras encontraram na habitação às margens da lagoa a principal estratégia de resistência coletiva ao processo de escravização. As narrativas de nossas interlocutoras quilombolas em campo remontam que a chegada das primeiras ancestrais, no século XVIII, foi por meio de barcos que aportaram nas águas da lagoa que banha o quilombo. Ali elas viveram e trabalharam e resistiram até o final de suas vidas. Diferentes hipóteses podem explicar o processo de ocupação da comunidade quilombola da Costa da Lagoa, dentre elas, que as ancestrais do quilombo vieram do Morro Alto $^{2}$ e se instalaram na beira da lagoa do Capivari. Outra hipótese é a de que as pessoas escravizadas migraram para a região para trabalhar (no ano de 1847) na construção de uma ponte imperial no município de Palmares no Rio Grande do Sul (INCRA, 2014). Entretanto, independente da hipótese de origem, o fato é que há mais de dois séculos há uma ocupação e uso coletivo do território quilombola da Costa da Lagoa.

Entretanto, com o passar do tempo, com o advento da "modernização da agricultura" na região, passaram a se intensificar disputas por (re)existência naquele território ancestral; isso diante das políticas de desenvolvimento que visavam tornar o local potencialmente "funcional" ao progresso e ao lucro, nas visões de produtores rurais e agentes de desenvolvimento regional. Assim, inúmeros aparatos sociotécnicos foram acionados e constituídos por agentes externos em prol de processos de apropriação econômica do ambiente. Com isto, as existências das famílias quilombolas e de inúmeros seres viventes passaram a ser constantemente ameaçadas. Entretanto, existem e (re)existem diversas dinâmicas de coabitação e cuidado nas terras "da Costa", como o convívio entre os grupos domésticos, a partir de lógicas de sucessão familiar para a ocupação das terras, e ainda de reciprocidade entre humanos e as figueiras centenárias que são, notoriamente, expressões da biodiversidade aprendida com os mais velhos e um patrimônio afetivo. Assim, a coletividade quilombola segue a constituir laços de parentesco e compadrio dentre as famílias negras que há inúmeras gerações habitam e cultivam dentre as taperas que costeiam a lagoa. Essas singularidades relacionais e espaço-temporais conformam o território ancestral da Costa da Lagoa.
1 O trocadilho da palavra resistência, que neste artigo é grafada como (re)existência, cumpre a função de marcar uma questão teórica e analítica cara a esta análise, pois o que está em questão neste caso estudado é a própria existência daqueles corpos e modos de vida no lugar que passou a ser considerado como funcional às políticas de desenvolvimento.

2 A comunidade quilombola do Morro Alto é situada no litoral norte do Rio Grande do Sul e está em processo de regularização fundiária no INCRA/RS. 


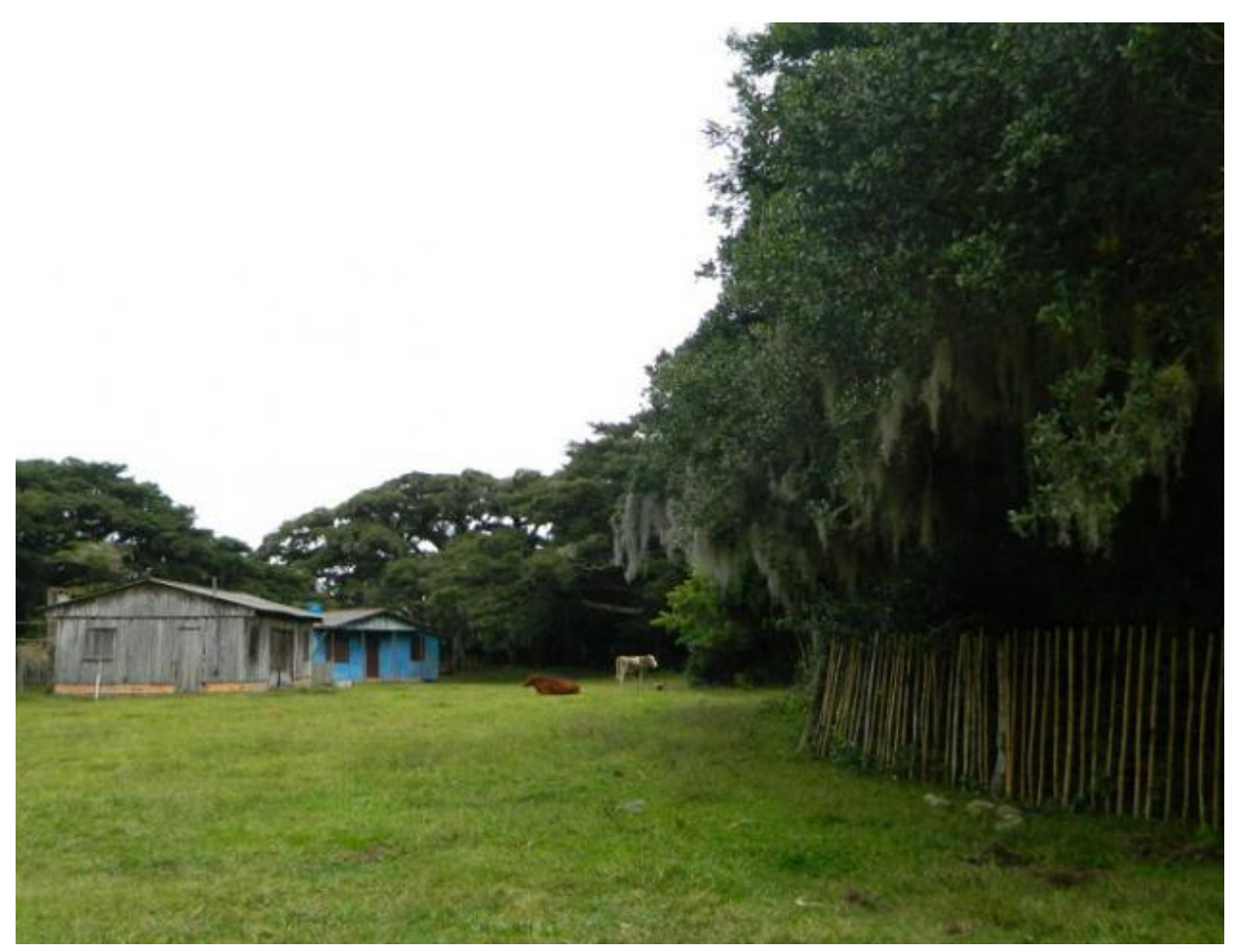

Evidencia-se que a Lagoa Capivari se reveste de grande importância para a comunidade, desde a gênese de sua ocupação pelos ancestrais, que vivenciaram os dilemas do cativeiro e forjaram seus projetos de liberdade. Segundo relatos que compõem a memória social do grupo e foram compartilhados no contexto de pesquisa descrita adiante, nas suas águas também surgiu uma importante forma de reprodução material da vida: o trabalho das mulheres constituído pela lavagem de roupas "pra fora” e a pesca predominantemente artesanal, praticada pelos homens. Além disso, as casas, desde há diversas gerações, eram construídas a partir do barro e do junco extraídos da lagoa.

O conceito de quilombo é abordado neste artigo a partir de uma perspectiva socioantropológica que considera o próprio giro historiográfico em relação à escravidão, com estudos que passam a priorizar em suas análises as estratégias pelas quais foram sendo produzidas brechas de autonomia e resistência a partir das experiências familiares de cativos (Slenes, 2011; Mattos, 1998), e prosseguiu em trajetórias partilhadas pelos idos do pós-abolição. Ilka Boaventura Leite (1999), ao mobilizar um denso repertório dos debates acerca da temática, considera a "vastidão de significados relacionados à dimensão política de uma formação social diversa no presente” (1999, p. 128). Sendo assim, são as dinâmicas e, também, as divergências a respeito dessa formação social diversa, e dos processos singulares que oportunizam elucidar, que buscamos enfocar neste trabalho.

Essa visão considera que a noção de territorialidade quilombola se funda numa espacialidade que emerge diante da "imposição de uma fronteira que é construída a partir de um modelo específico de segregação”, o que, argumenta Leite, "sugere a predominância de uma dimensão relacional, mais do que um tipo de atividade produtiva [...]” (1999, p. 137). Mas se os espólios e constrangimentos qualificam certos tipos de relações engendradas com a alteridade, de forma al-
Imagem 1 - Moradias em meio às figueiras centenárias. Fonte: Acervo do INCRA. 
guma encerram a potência de vida que compõe a trajetória coletiva do quilombo, nem as versões diversas de cada interlocutor ou interlocutora a nós narradas.

Nesse sentido, o território encarna e materializa referências e marcos territoriais "vivos", tecendo toda uma rede de pessoas, memórias e saberes que compõe as relações sociais da coletividade. Dessa forma, a sua preservação possibilita que - a partir da origem comum presumida na experiência colonial da escravização (O’Dwyer, 2002) - o grupo exerça formas de autonomia e criatividade a partir de tais referências. Contudo, esses processos de (re)existência são sustentados a partir de cosmologias e epistemologias, como é o caso das práticas relativas a ciclos de vida e de preparação de pessoas e celebração do sagrado, que serão abordadas adiante. Destacamos que tais manifestações não são fundadas numa relação de superexploração do ambiente, isto é, dos não humanos que coabitam no lugar. Portanto os conflitos e as disputas ambientais e (cosmo)políticas são abordadas neste artigo desde as perspectivas socioantropológicas que buscam se afastar da partição natureza e cultura (Latour, 1994; Strathern, 2014). Assim, a ideia de ambiente emerge nesta análise enquanto um espaço de hibridização entre sociedade e natureza (Fleury; Almeida; Premebida, 2014).

Nesse contexto, a especificidade que buscamos destacar nesta análise diz respeito a práticas de reciprocidade das pessoas negras da Costa da Lagoa com o ambiente, no lugar em que, ao longo do tempo, o grupo tem erigido um investimento relacional intenso. Referimo-nos ao sentido de uma coexistência que não tem por base um regime de exploração/comercialização das vidas não humanas. No caso desta comunidade, há diversas situações elucidativas das relações potentes que a coletividade quilombola aciona no ambiente, e de práticas que são apreendidas e repassadas por meio da vivência no grupo familiar, sobretudo em relação à força das águas da Lagoa.

Abordaremos "a força das águas" a partir de duas modalidades de práticas locais imbricadas aos ciclos de vida da coletividade: os batismos em casa e a festa de Nossa Senhora de Navegantes. Em comum, ambas as práticas familiares e comunitárias são vivenciadas na relação de coexistência das quilombolas com as águas da Lagoa do Capivari. No tópico seguinte, a dimensão da conflitualidade trará um movimento inverso, de barramento das águas e de experiências de constrangimento e expropriação territorial que afetaram a comunidade quilombola, sobretudo com o avanço da rizicultura na região da Lagoa do Capivari. A seguir, a experiência de produção do relatório técnico-científico que subsidiou o pleito territorial da Costa da Lagoa frente ao Estado brasileiro, e oportunizou nosso contato com o grupo, é trazida à reflexão inclusive em suas peculiaridades metodológicas. Por fim, os "Refúgios aos barramentos" são elucidados como potência de vida e como estratégia cosmopolítica, a partir das relações de longo prazo que os quilombolas da Costa têm estabelecido com as vidas não humanas que congregam esse território ancestral. Potência de vida que se prolonga entre as gerações de famílias negras, através dos saberes vividos e transmitidos nos ritos ligados aos ciclos de vida e celebração do sagrado, processos esses que, em vários aspectos, são distintos e dissonantes das políticas de apropriação e superexploração das águas da Lagoa pelas políticas designadas por desenvolvimento. 


\section{A força das águas}

Dentre as práticas que atualizam no presente relações de coexistência entre os quilombolas e os não humanos e performam a singularidade do território habitado, destacamos duas em particular: 1) os batismos dos recém-nascidos, realizados nas águas da Lagoa; e 2) a Festa de Nossa Senhora de Navegantes, que há mais de 50 anos é celebrada no segundo domingo de fevereiro, conforme veremos a seguir.

Recentemente tivemos a oportunidade de atualizar dados sobre a celebração dos batismos que tivemos acesso, inicialmente, durante o acompanhamento da elaboração do estudo técnico pela equipe do INCRA/RS visando instruir o pleito territorial comunitário. Conversamos com a quilombola Maria Joaquina Boeira, 78 anos, a Quina, a quilombola mais antiga e uma das principais interlocutoras durante o trabalho de campo para elaboração do relatório técnico que será tratado adiante. Ela nos relatou estar no quilombo em quarentena: "fazendo máscaras para distribuir, crochês e escrevendo sobre o pandemônio [maneira como ela prefere chamar a pandemia da Covid-19]". Na ocasião lhe contamos sobre a produção do artigo e nosso interesse renovado em saber mais sobre os batismos e sobre a Festa de Navegantes.

Quina nos indicou uma de suas irmãs mais novas que já realizou o batismo de algumas crianças e que aparenta ser a nova responsável do grupo pela transmissão desse conhecimento para que pudéssemos aprofundar o assunto. No entanto, a interlocutora indicada afirmou que não tinha informações novas para nos disponibilizar sobre o tema, ou talvez não naquele momento. Assim, optamos por apresentar as memórias que a Quina compartilhou conosco sobre a celebração dos batismos. De acordo com ela, todos eram convidados a se dirigir à beira da lagoa carregando flores, quando as crianças a serem batizadas eram vestidas com roupas brancas e colocadas no colo dos pais ou padrinhos. Nesse momento acontecia a reza em busca da proteção do anjo da guarda, que era conduzida pela cerimonialista da família. Ao final, era derramado um punhado de água da lagoa em suas faces.

Assim, a dupla vivência desse momento de preparação das pessoas, de certa forma, inscreve os novos parentes em um registro familiar territorializado. Com isto, podemos tecer aproximações com a análise a respeito das redes sociotécnicas componentes de especificidades territoriais e familiares dentre comunidades negras na região central do RS, em estudo que considera que "os corpos maturados no território desde muito cedo são inseridos em 'configurações relacionais' que interligam elementos de várias ordens" (RUBERT, 2007, p. 322). No caso dos ritos de batismo, tal maturação poderia ser atribuída à vitalidade da água que flui no entorno, do raminho de ervas cultivado em canteiros próximos das casas, geralmente a arruda, que deve ser molhada em um copo com água e um punhado de sal; e a chama da vela que usualmente é relacionada ao anjo da guarda da criança.

No caso da Costa da Lagoa, em relação aos batismos, vale considerar ainda que os mesmos não podem ser pensados desconectados dos eventos de nascimentos e dos funerais, pois esses três eventos estão inter-relacionados. Algumas ancestrais são lembradas como famosas parteiras da localidade, pois realizavam os 
partos de familiares em casa e assim todos os nascimentos, até a década de 1990, aconteciam no quilombo. Tais acontecimentos eram permeados por envolvimento coletivo e se constituem no presente um marcador de memória no grupo, é o que fica nítido nas palavras da quilombola Quina, conforme trecho de entrevista transcrito a seguir:

[...] A nossa mãe era parteira e eu tenho a espiriteira que ela esquentava a água, para molhar a tesoura e queimar. Álcool não existia, era querosene. Eles fechavam a porta do quarto, que geralmente não tinha porta, era só um pano pendurado, um cobertor. E o marido, o homem no caso, tinha que pegar o chapéu e andar na volta da casa (Entrevista com Maria Joaquina Conceição, realizada em 2013. In: INCRA, 2014).

Já em relação aos funerais, nos chamou atenção a descrição dela, de que "quando falecia alguém todas as vasilhas com água deveriam ser esvaziadas". Observamos, assim, que os ciclos de vida e de morte estão relacionados a qualidades diversas que são transpostas às águas da casa e requisitam um movimento de dispersão, de troca desse fluxo, quando se chega a um momento final no ciclo de vida.

A Festa de Navegantes acontece há mais de cinquenta anos e teve o seu início a partir do momento que uma ancestral encontrou na Lagoa uma imagem da santinha de Nossa Senhora de Navegantes. Desde então, este festejo passou a marcar um período no ciclo anual comunitário, em que o conjunto das relações de afeto e de parentesco que ele promove, como a circulação de pessoas, de artefatos, alimentos e inúmeras outras relações de trocas, são intensificadas. Todos os anos, ao final da festa, são escolhidos os festeiros dentre as parentelas dos "troncos", os quais passam a coordenar inúmeras atividades que acontecem o ano todo, para arrecadar fundos para a próxima festa e divulgá-la. Este é um momento de retorno ao quilombo, para muitas pessoas que se afastam em busca de trabalho.

Um dos momentos mais esperados durante os festejos que duram três dias nos dois primeiros dias são realizadas atividades desportivas e um baile - é a procissão que atravessa o território quilombola e que culmina com uma cerimônia na Lagoa do Capivari. Percorrer o quilombo é reviver os caminhos de resistência no lugar, ao longo do tempo, pois os lugares, tais como a "gruta da santinha", encarnam memórias comuns da trajetória de ocupação e das experiências devocionais que também estão inscritas na paisagem. Os novos encontros nesses sítios, em momentos de celebração, são oportunidades para o reavivamento e a atualização de tais práticas coletivas, as quais são perpassadas por devoções difusas que não se encerram num culto formal e nem se esgotam no momento da festa, pois as imagens estão espalhadas nas casas e nas orações cotidianas. 


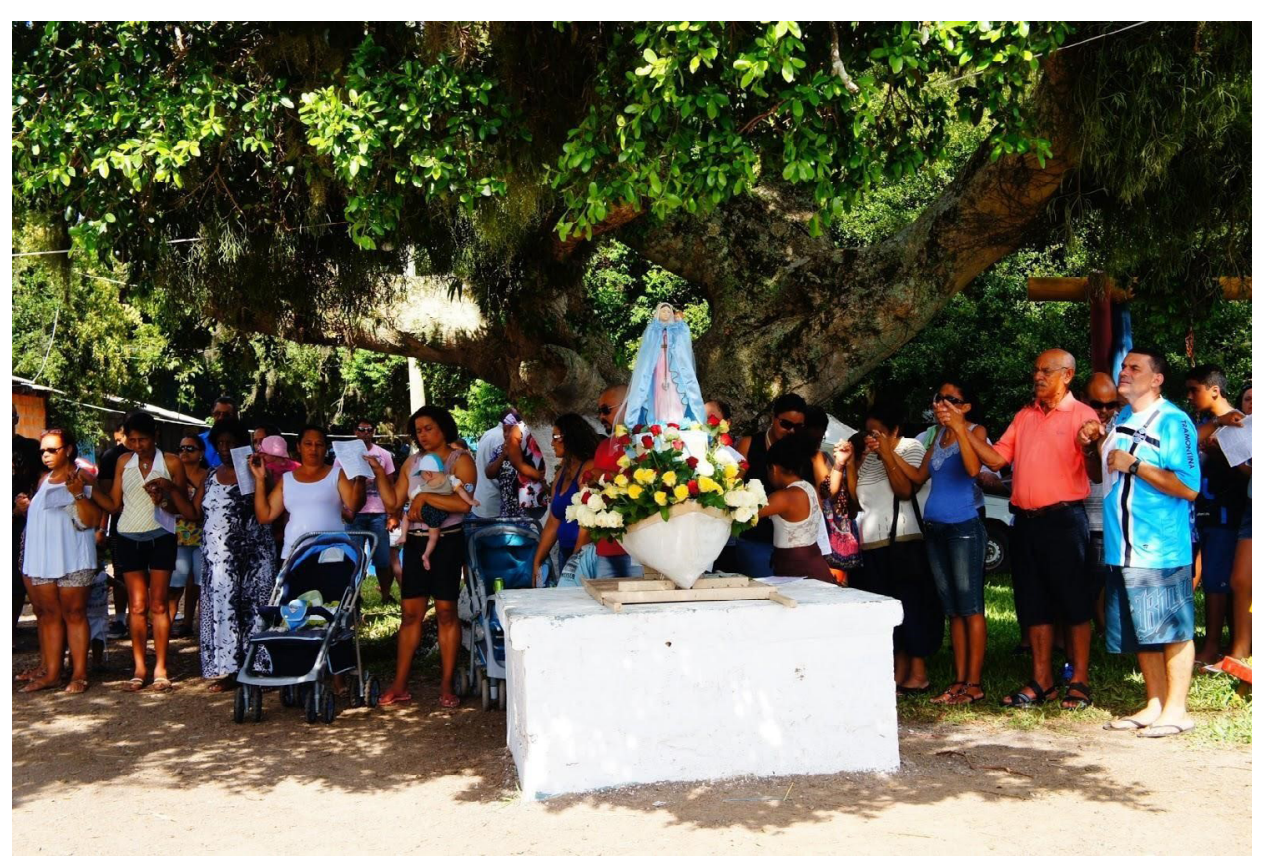

Contudo, em 2019, houve o destelhamento do salão comunitário da associação quilombola, alguns dias antes da realização da festa. Diante disso, o evento público que estava sendo divulgado foi cancelado, mas a procissão foi mantida. De lá para cá, a associação quilombola tem buscado acionar várias redes institucionais (prefeitura municipal, INCRA/RS, Ministério Público Federal, dentre outras), buscando angariar apoios e fundos para a reconstrução do salão. Infelizmente, em 2020, pela primeira vez depois de muitos anos, não ocorreu a procissão, pois a destruição da sede do salão coletivo teve inúmeros efeitos nas condições objetivas para realização de um evento desse porte e dos processos políticos que organizam e mobilizam a comunidade. Entretanto, a julgar pelos inúmeros agenciamentos que a comunidade quilombola conseguiu realizar ao longo do tempo, em defesa do direito de existir mesmo diante de situações extremamente adversas, acredita-se que o grupo possa encontrar caminhos para retomar a celebração. Observamos que os protocolos que envolvem a realização da Festa de Navegantes, durante o ano inteiro, possuem relação com acontecimentos cotidianos do grupo e desempenham um papel crucial no processo político comunitário.

Nem sempre a comunidade, que majoritariamente se define como católica, teve a presença da paróquia no quilombo na celebração da missa da Festa de Navegantes, no entanto, isso não impediu que os festejos e as celebrações pudessem ocorrer. Poderíamos nos questionar se os batismos nas águas, ou o também chamado "batismo em casa", surgiram a partir dessa recusa de reconhecimento da existência das pessoas quilombolas por parte da Igreja, ou se, ao contrário, a Igreja se recusava a reconhecê-los por conta de seus ritos específicos. No entanto, nos relatos partilhados durante a confecção do estudo técnico, essa suposta contradição nunca se colocou, pois declararam que costumavam realizar as duas formas de batismo, em casa, nas águas da lagoa, e depois na Igreja.

De toda forma, a transmissão de tais saberes locais perpassa gerações, sobretudo de núcleos familiares de mulheres quilombolas, como é o caso de Maria
Imagem 2 - Após o

deslocamento de Nossa

Senhora de Navegantes

da grutinha até a frente do

salão comunitário, acontece

a missa embaixo de uma

figueira. Quando, então, a

imagem da santa repousa

num barco de flores que

simboliza a força das águas.

Após a celebração, acontece

a procissão até a Lagoa do

Capivari quando os devotos

carregam o barco pelas

águas.

Fonte: Acervo do INCRA. 
Joaquina, que congrega e mobiliza as memórias coletivas legadas por sua avó, por sua mãe, por suas tias e primas e hoje aponta para uma nova responsável pela realização dos batismos em sua família.

\section{As expropriações territoriais e o avanço da rizicultura}

As primeiras narrativas que ouvimos ao chegar no quilombo da Costa da Lagoa para a realização do estudo técnico versavam sobre as perdas das áreas ocupadas pelos familiares mais antigos, devido a inúmeras situações de vulnerabilidade social e territorial que enfrentaram ao longo do tempo. Tais formas de violência e desterro podem ser exemplificadas nas afirmações das nossas interlocutoras quilombolas, as quais ouvimos em campo, tais como: "ali ficava a roça de aipim do falecido tio Pedro que ele trocou por sacos de farinha quando perdeu a roça devido à seca", ou então: "aquela parte ali o meu avô trocou por um cavalo encilhado". Tais narrativas apontam para perdas materiais, mas também para situações de constrangimento. Segundo relatos, a comunidade vivia em meio a inúmeros alagamentos: "quando chovia tudo aqui virava lagoão"; diante de tal situação de inundação, imagine-se a importância que poderia ter um cavalo encilhado para a locomoção no lugar, por exemplo. Essas renúncias de partes de suas terras, para não morrer de fome, ou para ter um meio de locomoção, dentre outras razões de sobrevivência, são reveladoras das marcas do racismo, pois as territorializações que mantiveram, mesmo diante de um acúmulo de vivências, remetem à condição de subalternidade relacionada ao processo de escravização sofrido por suas ancestrais.

Igualmente, as quilombolas nos relataram várias situações relacionadas ao início das lavouras de arroz. Essas que foram ocupando as terras no entorno da lagoa do Capivari a partir da década de 1970, sem que as quilombolas tivessem força para impedir que constantemente "as cercas fossem andando". Conforme demonstrou a pesquisa realizada pelo INCRA, no contexto das chamadas políticas de modernização da agricultura (ou "revolução verde"), houve a prevalência de várias intervenções sociotécnicas que degradaram as condições de vidas não humanas e promoveram um achatamento da tessitura social no local. Essas políticas despertaram o interesse econômico nas terras tradicionais e nas proximidades, as quais antes eram ocupadas pela população negra e por vizinhos.

Assim, da mercantilização dos "recursos" naturais, neste caso especialmente da exploração da água da Lagoa Capivari, advieram esbulhos ${ }^{3}$ das terras tradicionalmente ocupadas pelo grupo que se autorreconhece como quilombola (INCRA, 2014). De tal situação, decorreu uma ainda maior vulnerabilidade territorial, já que esse território se tornou alvo da especulação fundiária devido à abundância do "recurso" hídrico. Nesse contexto, se dá a inscrição do espaço tradicional enquanto um potencial ao desenvolvimento e às suas consequências.

No que diz respeito aos processos sociotécnicos, apoiamo-nos naquelas abordagens que procuram "reagregar o social" a partir da cartografia das diferentes redes híbridas formadas por inúmeras associações entre atores e actantes, as quais conformam as materialidades que convencionamos chamar de social ou sociedade (Latour, 2012; Callon, 1999). Deste ponto de vista analítico, assume-se que a
3 No sentido jurídico, refere-se ao ato de usurpação pelo qual uma pessoa é privada, ou espoliada, de coisa de que tenha propriedade ou posse (Brasil, 2016). 
realidade está sempre envolvida em inúmeras controvérsias e incertezas (LATOUR, 2016), as quais podem ser evidenciadas a partir da descrição das associações que acontecem em tais redes. $\mathrm{O}$ não reconhecimento dessas relações híbridas produz o que a Teoria do Ator-Rede (Actor-Network Theory) caracteriza como processos de "purificação", ou seja, a desconsideração e o achatamento das inúmeras associações e agenciamentos que ocorrem nas diferentes redes sociotécnicas, até que os enunciados sejam pacificados e considerados como não sujeitos a controvérsias.

Nesse aspecto, as "técnicas" e seus aparatos político-discursivos, como destaca James Ferguson, cumprem o papel de "máquinas de antipolítica” (FERGUSON, 1990), na medida em que funcionam como formas de desconsideração às inúmeras desigualdades que carregam as políticas de desenvolvimento. $O$ autor, ao debater os efeitos de tais políticas, apresenta reflexões fundamentais para o debate das ciências sociais, especialmente para àquelas análises que se situam no âmbito da crítica ao "desenvolvimento", como, aliás, se pretende a abordagem aqui realizada. O autor se insurge analiticamente contra a "indústria do desenvolvimento", a qual traz em si uma "expectativa de modernidade" e "um conjunto de quase promessas" de direitos a partir do capitalismo, que tem a especificidade de ser "um motor de acumulação e de produção" 4 (Ferguson, 2011, p. 190).

Adriana Paredes Peñafiel, no artigo Relações do alimentar e relações que alimentam: El Tambo e a Mamacocha no norte do Peru, a partir de uma narração e de uma análise densa sobre as relações de proteção que os camponeses do norte do Peru estabelecem com a Lagoa Mamacocha que é alvo de um projeto de mineração, demonstra as inúmeras disputas ontológicas que se conformam em torno dessa temática. Por um lado, a defesa do desenvolvimento e da técnica que são propugnadas para justificar a espoliação mineral. Por outro lado, a recusa dos camponeses de que seja mexido nas águas profundas da lagoa, pois consideram que isso pode gerar consequências materiais e imateriais irreparáveis para inúmeras existências humanas e não humanas que se alimentam dela (Paresdes Peñafiel, 2015). Essas convicções cosmológicas têm propiciado inúmeros agenciamentos que os camponeses peruanos realizam para realizar uma verdadeira vigília de suas águas, como uma forma de (re)existência e de trancamento dos projetos de mineração.

No caso em análise neste artigo, importa destacar que parte significativa do território tradicionalmente ocupado pelas parentelas quilombolas da Costa da Lagoa foi esbulhada pelo advento das lavouras de arroz, que realizaram a espoliação da água da lagoa a partir do entubamento da Lagoa Capivari e das várzeas adjacentes, no intuito da irrigação, a partir da década de 1970. Essas técnicas que foram utilizadas para canalizar esse "recurso" hídrico transformaram a lagoa e o ambiente circundante, considerando o embarramento ${ }^{5}$ que foi ocasionado devido ao drenamento do solo extremamente encharcado para a viabilização das lavouras. Tal drenagem levou à formação de sedimentos, que restaram depositados na lagoa. Da mesma forma, houve a poluição das águas pelo uso de venenos nos plantios (INCRA, 2014). Tais mudanças e intervenções técnico-científicas aprofundaram a vulnerabilidade territorial e econômica das quilombolas, pois várias de suas atividades, como a pesca artesanal, foram afetadas; assim, muitas delas passaram
4 Kant de Lima (2011), ao entrevistar o antropólogo James Ferguson no Brasil, revisa os debates da antropologia econômica a partir da premissa de que a existência das trocas não é o problema. E, sim, a acumulação e a desigualdade que elas geram. Para ilustrar esse contraste, ele traz um exercício genealógico em que demonstra que "algumas sociedades decidiram não acumular, optaram por destruir, distribuir ou, qualquer outra coisa. Mas, a nossa sociedade, em certo momento da história, decidiu-se acumular, e esse é o sistema capitalista com que estamos lidando" (Lima, in: Ferguson, 2011, p. 189).

5 Refere-se às terras argilosas aplicadas nos intervalos das paredes de taipas que represam ou drenam as águas. 
a depender dos parcos empregos nas lavouras de arroz, diante do processo de mecanização da atividade agrícola incidente.

Em consonância às reflexões de Paul Gilroy, as dinâmicas descritas de disputa pela terra e recursos subjacentes nos convocam à análise sobre as relações das pessoas negras com a modernidade ocidental. $O$ autor considera que há uma estreita relação entre modernidade e escravização. Para ele, essa é decididamente uma questão chave, "porque ela pode ser usada para fornecer uma firme rejeição à ideia hipotética da história como progresso" (Gilroy, 2001, p. 122). Tal perspectiva analítica é elucidativa dos processos de subalternização e subordinação das pessoas e corpos negros, na medida em que a chave modernidade-escravização emerge a partir de processos de "terror racial", que ora se manifestam em exploração das forças de trabalho, ora como apagamento dos saberes ancestrais e potências de vida.

\section{Saberes em rede: a produção do relatório técnico-científico}

A coletividade quilombola, ao longo do tempo, tem demonstrado capacidade de agenciamento de diferentes atores e instituições, as quais são mediadoras e/ou promotoras de políticas públicas relacionadas à garantia dos direitos quilombolas por parte do estado brasileiro. Exemplo disso, foi a abertura do Processo Administrativo junto ao INCRA em 2011, o que se deu com a mediação do Ministério Público Federal através de um Inquérito Civil Público. Esse inquérito foi instruído a partir de alegações significativas da comunidade sobre a relação de conservação e respeito exercida pela comunidade quilombola em relação à Lagoa Capivari. Observamos que o processo de autorreconhecimento junto à Fundação Cultural Palmares data de 2006, mas somente em 2011 foi aberto o processo de regularização fundiária no INCRA/RS, e isso coincidiu com o momento em que terceiros não quilombolas haviam ocupado áreas de posse da comunidade e cercado parte do acesso à Lagoa, conforme veremos a seguir.

A nossa inserção em campo aconteceu a partir de 2012, após um novo concurso do Instituto Nacional de Colonização e Reforma Agrária $^{6}$ - o último ocorrido -, quando ingressamos no INCRA/RS no cargo de Analista em Reforma Agrária e Desenvolvimento Agrário-Habilitação: Antropologia. Uma das primeiras comunidades em que atuamos foi a comunidade quilombola da Costa da Lagoa. À época, estávamos acompanhando a elaboração de relatórios antropológicos por meio de um pregão em comunidades que estavam na "fila" há mais tempo (considerando o tempo de abertura do processo administrativo) e que, por esse critério, atingiram a fase da elaboração do Relatório Antropológico (RA) ${ }^{7}$, que é a primeira peça do Relatório Técnico de Identificação e Delimitação (RTID). Entretanto, uma demanda ambiental emergiu em relação à comunidade quilombola da Costa da Lagoa que foi apresentada pela associação quilombola ao Ministério Público Federal (MPF) que acionou o INCRA e solicitou providências para que essa comunidade fosse atendida imediatamente. Isto é: recomendou que, em função dos conflitos ambientais incidentes, aquele processo administrativo deveria subir na "fila". O conteúdo da controvérsia se referia ao cercamento e à poluição da Lagoa do Capivari que banha a comunidade quilombola da Costa da Lagoa.
6 No que se refere à titulação dos territórios quilombolas, a partir do Decreto 4887/2003 (Brasil, 2003), surge uma demanda crescente por contribuição de profissionais em antropologia para a elaboração de relatórios técnicos de caráter sócio-histórico-antropológico, visando subsídio aos pleitos territoriais de comunidades quilombolas junto ao INCRA. Nesse novo cenário, o Estado brasileiro passou a promover concursos públicos para o INCRA para o cargo de Analista em Reforma e Desenvolvimento Agrário - Habilitação Antropologia.

7 A Instrução Normativa $n^{0}$ 57/2009 do INCRA define, no seu artigo 10 , um conjunto de quesitos técnicos para a elaboração do Relatório antropológico de caracterização histórica, econômica, ambiental e sociocultural da área quilombola identificada (INCRA, 2009), que neste trabalho abreviamos como Relatório Antropológico 
Logo em seguida, o INCRA foi acionado para responder sobre um usucapião que incidia numa parte da área do território da comunidade na qual havia uma posse precária de um não quilombola. Dessa forma, fomos convocadas para participar de uma vistoria ${ }^{8}$ da área em questão, juntamente com o agrônomo do setor. Ao chegar na comunidade, constatamos que o processo de usucapião atingia o salão comunitário da comunidade, o qual havia sido construído no local onde era a casa da "vó Tita", a Serafina - avó de nossas interlocutoras e parteira da comunidade. Diante dessa informação, ficou nítida a urgência do início da pesquisa antropológica, pois estava em questão a manutenção da trajetória de resistência da comunidade no lugar, que se mantinha desde o período da escravização. Naquele salão comunitário eram realizadas inúmeras atividades e práticas da comunidade, dentre as quais, conforme nos relataram as nossas interlocutoras em campo, a Festa de Navegantes.

A pesquisa para a elaboração do Relatório Antropológico foi desenvolvida durante 18 meses, com alguns momentos de hospedagem na comunidade, ou nos arredores e de outras idas e vindas constantes. Antes do início dos trabalhos de campo, foram realizados alguns processos de mediação junto à rede institucional afeta aos direitos quilombolas. Para tanto, além da comunicação por escrito aos órgãos sobre o início do RTID, foi realizada uma reunião no quilombo, com a presença de vários órgãos, tais como: a gestão do INCRA, o Ministério Público Federal (MPF), a Federação Quilombola e a Emater/RS, dentre outros. Após esses ritos políticos-administrativos, prosseguimos a imersão no campo. Iniciamos com uma reunião da equipe ${ }^{9}$ com a comunidade onde foram informados os objetivos e o formato dos trabalhos a serem desenvolvidos.

Desde então, foram estabelecidas relações de trocas com as interlocutoras quilombolas mais antigas e com as dirigentes da Associação. Na ocasião, informamos sobre o nosso termo de referência e convidamos os participantes para realizarem uma pesquisa em seus arquivos de fotos e de documentos, os quais sustentariam a pesquisa, juntamente com o acionamento da história oral que seria reconstituída a partir das memórias, via entrevistas a serem realizadas e, especialmente, através do convívio com parte do cotidiano da comunidade. A partir de então, passamos a seguir as pistas de nossas interlocutoras sobre as pessoas a serem entrevistadas e sobre os lugares que encarnavam sinais diacríticos da trajetória de ocupação e resistência da comunidade no território. Dessa forma, fomos construindo uma etnografia que buscou reconstruir não apenas a trajetória de resistência ao longo do tempo, nas fronteiras porosas de pertencimento étnicorracial, mas também dar relevo e visibilidade às diversas formas como as relações de parentesco, de solidariedade, vizinhança no território e as festividades atualizavam as relações de pertencimento e de alteridade com o ambiente no presente. As partilhas de um senso de trajetória comum aos atores sociais envolvidos (O'DWYER, 2002), bem como, as relações com a alteridade, nas fronteiras de sentidos, memórias e moralidades - que orientam, mas também contrastam práticas coletivas situacionalmente - constroem as diferentes formas de pertencimento étnico (BARTH,1998).

Desde a vistoria de que participamos, por ocasião do usucapião e anteriormente citada, mantivemos contato permanente com a quilombola Talita Conceição
(RA).

8 O trabalho técnico com comunidades quilombolas no INCRA é de natureza multidisciplinar. Tal circunstância é enriquecedora, entretanto, as previsões normativas, muitas vezes, estão em descompasso com os procedimentos de construção do conhecimento que são caros às ciências humanas. Bem como, a interlocução com as outras áreas, em algumas circunstâncias, ainda são obstaculizadas devido às incompreensões acerca do papel social do qual a antropóloga não pode prescindir, no sentido proposto por Eliane O’Dwyer (2010) de valorização da capacidade reflexiva da disciplina na mediação do diálogo intercultural, imersos nas nossas responsabilidades

sociais e profissionais.

9 Contamos com a valiosa colaboração do nosso colega agrônomo Mário Stringhini , da estagiária Lisey Silveira da Silva e da colega antropóloga Naíra Daubermann. E, ainda, do bacharel em História Lucas Nunes de Souza como um colaborador eventual da pesquisa, já que na equipe de quilombos 
Ferraz, 75 anos, irmã da Quina. A convivência com ela e a sua colaboração foram decisivas para o desenvolvimento do estudo antropológico, pois ela caminhava muito conosco pelo território, nos mostrava os lugares dos antigos, as criações naturais. A exemplo de uma figueira em que até alguns anos atrás eram vistas as marcas das correntes de um possível tronco, ou outra que fornecia a casca de que eram feitos utensílios para beber água. $\mathrm{O}$ que, destacamos, revela constantes processos de coprodução das vidas diante das dificuldades enfrentadas. Aquela mulher quilombola também nos indicava as visitas a serem feitas e propunha entrevistas e as realizava, em partes, pois ela detinha grande capacidade de diálogo e arguição junto à sua parentela e aos seus vizinhos. Também nos levava em taperas/ruínas, tais como a da Ponte Imperial de Palmares do Sul, e ainda nos acompanhava em algumas idas ao cartório de registros de documentos.

Ao iniciar a pesquisa e a inserção em campo, tínhamos a informação compartilhada pelo grupo de que a ocupação da Costa da Lagoa era fruto de uma "dádiva" de terras, a qual as ancestrais mais antigas haviam recebido. Com o decorrer da pesquisa nos arquivos históricos, encontramos um inventário (do ano de 1878) de um "senhor de terras" que continha um legado de terras na região onde se situa a comunidade, o qual foi deixado a uma das integrantes mais antigas de um dos troncos da comunidade, a Delfina, mais conhecida como Dede. Inicialmente, tivemos muitas dúvidas sobre como abordar essa situação com as quilombolas, pois a informação do testamento (propriamente dito) tratava-se de uma "hipótese externa”, já que as nossas interlocutoras quilombolas mantinham a convicção de que havia um legado de terras às suas ancestrais. Entretanto, elas desconheciam a informação de que a ocupação fática negra havia sido registrada, ao menos parcialmente, em um testamento. Ao tomar conhecimento de tal registro cartorial, as nossas interlocutoras quilombolas consideraram que fazia sentido que a "Delfina do testamento" fosse a Dede, até mesmo porque a idade dela conferia com o assento de batismo ${ }^{10}$ que encontramos na Cúria da Igreja Católica do município de Osório (Rio Grande do Sul), em que ela foi registrada como nascida em 1870 como filha de Damásia, escravizada de Antônio Domingues de Oliveira Brás.

Durante a elaboração do Relatório Antropológico, tivemos a oportunidade de entrevistar o sobrinho-neto do senhor Antônio Brás, o escravagista que deixou o legado de terras para a Delfina. Aquela foi uma experiência significativa, pois a quilombola Talita nos acompanhou na visita e embora no início ela tenha apenas escutado, diferentemente da interação que costumava exercer, nós guardamos convicção de que ela não se intimidou. Aquele senhor, Pedro Brás (82 anos, à época), nos recebeu de forma cordial e afirmou que desconhecia o registro cartorial do testamento. Entretanto, ele não se surpreendeu com o legado do testamento às quilombolas, pois reconheceu que: "[..] ali [na Costa da Lagoa] fazia parte da Sesmaria São Bernardo, e os negros sempre viveram ali, aquela terra sempre foi ocupada por eles e se alguém falar o contrário, estará mentindo (Pedro Brás, entrevista realizada em junho de 2013. In: INCRA, 2014).

Após abordar a dimensão ética com nossas interlocutoras, relativa ao manejo pela pesquisa daquela relevante informação cartorial que envolvia o registro do do INCRA não há analistas em História.

10 Naquela ocasião fizemos o primeiro contato com esse tipo de documentos, os quais são arquivados nas Cúrias da Igreja Católica. Nos chamou a atenção que em tais registros paroquiais havia dois tipos de classificações: 1) o nome e o sobrenome da pessoa seguido de "livre", ou, 2) somente o primeiro nome da 
legado de terras ${ }^{11}$, e que até então não era de conhecimento da comunidade, a ancestral Delfina teve a sua trajetória de vida inventariada pela comunidade. Assim, passaram a circular algumas fotografias dela, as quais foram exaltadas e comemoradas pelas quilombolas envolvidas na pesquisa. A partir desse marco, muitas memórias foram acionadas; e esse processo de reavivamento das lembranças que envolviam a memória da convivência com a Dede possibilitaram que a narrativa da comunidade ficasse mais fluida em relação ao conjunto da pesquisa, pois essas reminiscências ganharam uma potência enunciativa no presente.

Dessa forma, a elaboração do Relatório Antropológico da Costa da Lagoa (no período de 2013 a 2015) e o acompanhamento do processo de reconhecimento junto ao INCRA/RS nos trouxeram e continuam trazendo vários questionamentos em relação ao exercício de nosso ofício, à escrita etnográfica e às condições autorais envolvidas em nossas pesquisas com esses sujeitos sociais em luta. Elucidativa de tais questões éticas e procedimentais foi a iniciativa da quilombola mais antiga à época da nossa pesquisa, Maria Joaquina Boeira da Conceição, $78 \operatorname{anos}^{12}$, a já referida Quina, que elaborou o documento $A$ vida quilombola e o entregou a nós nos primeiros dias da pesquisa. Aquele texto, de 15 páginas, versava sobre os modos de vida no território, como festas, batizados, funerais, comidas “típicas", ervas medicinais e objetos que encarnavam as memórias (e memoriais) de momentos de vulnerabilidade que vivenciaram, bem como continha informações relevantes sobre a diversidade de alternativas e soluções que emergiram na inter-relação no ambiente.

Tal documento nos forneceu pistas cruciais sobre os caminhos da pesquisa e nos levou a questionar os limites da própria autoria da peça técnica que era construída. Não porque o texto quilombola que nos foi entregue esgotasse a nossa pesquisa e os próprios protocolos analíticos e teóricos (caros ao nosso ofício) que a sustentavam, mas porque tal situação evidenciou que essas histórias e trajetórias que buscamos descrever e restituir foram escritas das mais diversas formas por esses sujeitos sociais, protagonistas de seus modos de vida. Essas histórias não constam em nenhum "livro oficial" da história única (Adichie, 2019), pois, ao longo do tempo, foram desconsiderados em seus próprios estatutos intelectuais.

Diante de tais impasses analíticos, a estratégia que encontramos naquele momento foi buscar uma forma de "bifurcação" (Strathern, 2013; Morawska, 2017) ${ }^{13}$ entre as exigências normativas, os aportes disciplinares e o protagonismo da enunciação das mulheres quilombolas que estavam engajadas na pesquisa que estávamos realizando. Pesquisa e/ou estudo técnico que, naquele momento, não era mais apenas da equipe de colegas "especialistas", pois esse se tornou também o momento que a comunidade encontrou para elaborar suas próprias formas de enunciação e registro de memórias. E elas e eles o fizeram a partir do inventário daquilo que era diacrítico para si: os costumes vindos das antigas, as festividades, os parentescos, as fotos e documentos antigos e, muito especialmente, a reconstituição dos laços genealógicos, as “árvores”, que despertaram um notório envolvimento e adesão à pesquisa. Boa parte das entrevistas realizadas eram desenvolvidas a partir das lembranças dos vínculos de parentesco e dos lugares das "antigas" (troncos) no território. pessoa seguido da designação "escravo" de fulano de tal.

11 No Rio Grande do Sul existem inúmeros legados testamentais de terras de quilombos a famílias de pessoas escravizadas. O exemplo mais notório é o testamento do quilombo da Casca (Mostardas/Rio Grande do Sul), que emergiu a partir da pesquisa inaugural da temática quilombola no Rio Grande do Sul, que foi coordenada pela antropóloga Ilka Boaventura Leite (Leite, 2005 ). Esse e outros registros são expressões do reconhecimento de parte da realidade fática da existência e da permanência de territórios quilombolas. Entretanto, na maioria dos casos, com exceção do quilombo da Casca, tais processos de reconhecimento e titulação territorial permanecem inconclusos, pois há um enorme hiato entre o direito fundamental que é a titulação quilombola (Brasil, 1988) e a obrigação do estado brasileiro de cumprir tais preceitos constitucionais.

12 A quilombola Maria Joaquina (a Quina) alimenta o hábito da escrita constantemente. Exemplo disso foi o envolvimento dela na pesquisa de dissertação de uma colega nossa de trabalho, sobre escritas ordinárias de mulheres negras (Daubermann, 2019). Ou, ainda, as suas reflexões recentes sobre a pandemia do coronavírus. Aliás, um trecho de tais escritos, transcrito a seguir, é elucidativo de uma cosmovisão que é tecida a partir de relações de alteridade com o ambiente: “[...] estamos anestesiados, não abraçamos quando podíamos passamos o tempo todo ignorando tudo, a natureza, os animais, planetas, o mar, as estrelas, os pássaros, os germes do ventos, as cachoeiras" (Conceição, 2020).

13 Catarina Morawska (2017), ao se referir à renovação do empreendimento comparativo em antropologia realizado por Marilyn Strathern (2004), o qual explicita "as aproximações, paralelos e transformações dos conceitos nativos em relação aos conceitos oriundos da teo- 
Essas evocações e acionamentos da memória da luta e resistência a partir do território também eram perpassadas por momentos de silêncios e afasias sobre aquilo que não se queria enunciar, pois como nos disse uma das quilombolas durante a pesquisa, "existem coisas que é melhor esquecer". Momentos como aquele são oportunidades de desestabilização de pressupostos, pois demonstram que, embora em algumas ocasiões as fronteiras da pesquisa possam ser "borradas"14 (Strathern, 2014), e até mesmo que a nossa inserção etnográfica possa se converter em compartilhamento de parte do cotidiano com as nossas interlocutoras - o que no caso da pesquisa na Costa da Lagoa nos propiciava inúmeras e significativas trocas, tais como cozinhar, comer, descansar, falar também sobre a nossa vida pessoal e desfrutar do convívio familiar -, entretanto, os silêncios de nossas interlocutoras devem ser ouvidos, pois nos fazem lembrar que existe um limiar daquilo que não é passível de ser transformado (ou talvez esvaziado) em escrita antropológica. Tanto quanto o aprendizado de que os potenciais relacionais e a variabilidade de estratégias de enfrentamento à violência racista que impacta as vidas dos moradores da Costa da Lagoa é diversa, e não necessariamente corresponde à lógica estatal, quando requer uma formulação de proposta de pleito territorial.

\section{Território vivo e os refúgios aos barramentos}

Ao longo dos tempos, as famílias quilombolas da Costa da Lagoa têm encontrado formas eficazes - mas não livres de conflito e de momentos de opressão - de exercer uma cosmopolítica (Stengers, 2018; Latour, 2016) através das relações de longo prazo com as vidas não humanas que congregam esse território ancestral e suas relações sociais. Essas relações foram aqui abordadas a partir das práticas que remetem a importantes ciclos de vida da coletividade negra, como os batismos "em casa" e as festas de Nossa Senhora de Navegantes, ambas realizadas nas águas da Lagoa Capivari. Neste caso, o termo cosmopolítica está diretamente relacionado à luta por coexistência das vidas humanas com as demais formas de vida, e um foco de saberes e práticas locais os quais em vários aspectos são contrastivos com as políticas de desenvolvimento que veem nos "recursos naturais", simplesmente ativos econômicos, destinados a superexploração, a exemplo do histórico de tentativas de apropriação privada das águas da Lagoa Capivari para a rizicultura. Bruno Latour (2016) sumarizou o conceito de cosmopolítica, a partir de Isabelle Stengers (2015), mais ou menos nos seguintes termos: enquanto uma junção da "política com o cosmos", ou seja, nem o cosmos nem a política sozinhos, ambos inter-relacionados.

Essa inter-relação com as águas congrega, ao nosso ver, um leque de inscrições diaspóricas (Gilroy, 2001) evocadas pela memória coletiva através de relatos orais que perpassam desde a chegada dos ancestrais ao local, ainda como cativos, seja na versão do local de refúgio aos que resistiram à escravização; seja no diálogo com as fontes documentais analisadas durante a elaboração do relatório técnico e que atestam uma doação de terras às ancestrais negras. A esses relatos fundantes somam-se temporalidades e saberes adscritos ao cultivo de junco e pesca artesanal, a sombra e proteção das figueiras, e a aparição de uma represen- ria", aposta que tais encontros de externalidades provocam

"novas aberturas e conexões"(Morawska, 2017, p. 240).

14 Strathern (2014) sustenta que o trabalho de campo do (a) antropólogo (a) precisa se desafiar a repensar as "molduras" da pesquisa e a borrar as fronteiras dicotomizadas pelas perspectivas etnocentristas, que colocavam pesquisador e o pesquisado em polos irremediavelmente separados. 
tação da santa que iniciou as celebrações anuais à Nossa Senhora de Navegantes.

A luta recente por reconhecimento étnico-racial e demarcação territorial enquanto quilombolas torna-se um flanco de disputas, talvez mais uma das estratégias empreendidas na disputa por quais mundos podem coexistir diante dos ideários modernos de lucro e progresso. Em nossa compreensão, com base no acompanhamento do processo administrativo visando à regularização fundiária das terras da Costa da Lagoa, tal empreendimento relacional não necessariamente diluiu a intensidade de outras práticas e conhecimentos repassados entre as gerações como formas de resistência local. O investimento recente do grupo no viés de acesso à política pública para a regularização fundiária de seu território aponta para um novo flanco de resistência coletiva, e que demanda um acompanhamento dos desdobramentos futuros deste processo. Durante a realização do estudo técnico que oportunizou as nossas primeiras trocas com o grupo, pudemos aprender com nossas interlocutoras que mesmo diante de inúmeras situações adversas que conformam não somente confinamentos territoriais, mas também existenciais, as quilombolas vêm fazendo frente a essas ameaças desde múltiplas práticas e políticas exercidas ante as precariedades que os impactam.

Nesse sentido, podemos tecer aproximações entre as vivências e temporalidades ora narradas e a proposição política do Chthuluceno, enquanto uma possibilidade de "reconstituir refúgios, para tornar possível uma parcial e robusta recuperação e recomposição biológica-cultural-política-tecnológica" (Haraway, 2016, p. 141). Destarte, tais perspectivas, propostas por Donna Haraway e outras autoras, consideram pluralidades ontológicas que contrastam com o antropoceno, que é caracterizado por essa era geológica de inúmeras mudanças drásticas no planeta a partir da ação humana, podendo assim ser definido também como uma "era da perturbação humana e de destruição em massa" (Tsing, 2019, p. 23). Anna Tsing sustenta que estamos diante de uma diversidade cultural e de uma biodiversidade contaminada, as quais fundam as paisagens no antropoceno. Em sentido semelhante, a ocupação ancestral da Costa da Lagoa, através das diversas formas de luta pela conservação do território e da defesa da coexistência de vidas humanas e não humanas que coabitam na paisagem pode ser considerada como um meio de defesa de um "refúgio", tanto nas formas de resistência à escravização quanto no presente através da manutenção daquele lugar, em meio aos efeitos dos manejos técnico-científicos advindos das políticas de desenvolvimento.

\section{Considerações finais}

O acionamento e o respeito à força das águas da lagoa por parte da coletividade quilombola contrastam frontalmente com as intervenções sociotécnicas que chegaram ao local com o avanço da rizicultura na região do litoral gaúcho, sendo que o barramento das águas para uso no cultivo das lavouras de arroz ocasionou processos de assoreamento, despejo de venenos e morte de peixes, além de tentativas de espoliação territorial. Observa-se, assim, que os não humanos, que também têm as suas existências ameaçadas, são os principais aliados na disputa ontológica que as quilombolas sustentam na Costa da Lagoa, pois a conservação 
da paisagem confere potência à luta das quilombolas por suas existências. Dessa perspectiva relacional, o grupo quilombola reafirma e potencializa as suas memórias, seus saberes e cosmoideias a partir de uma perspectiva que é não instrumental e, sim, é erigida em ciclos de vida e transmitida às novas gerações.

Recebido: 09/03/2020

Aprovado: $23 / 06 / 2020$ 


\section{Referências}

ADICHIE, Chimamanda Nigozi. O perigo de uma história única. São Paulo: Companhia da Letras, 2019.

BARTH, Fedrik. Grupos étnicos e suas fronteiras. In: POUTIGNAT, Philippe. Teorias da etnicidade. Seguido de grupos étnicos e suas fronteiras de Fredrik Barth, Philippe Poutignat, Jocelyne Streiff-Fenard. Trad. de Elcio Fernandes. São Paulo: Editora da UNESP, 1998.

BRASIL. Constituição da República Federativa do Brasil. Promulgada em 5 de outubro de 1988. Brasília. 2008. Disponível em: http://www.planalto.gov.br/ccivil_03/constituicao/constituicao.htm. Acesso em: 24 jun. 2020.

BRASIL. Decreto 4887/2003. Regulamenta o procedimento para identificação, reconhecimento, delimitação, demarcação e titulação das terras ocupadas por remanescentes das comunidades dos quilombos. Brasília. 2003. Disponível em: http://www. planalto.gov.br/ccivil_03/decreto/2003/D4887.htm. Acesso em: 24 jun. 2020.

BRASIL. Lei n 13.105, de 16 de março de 2015. Institui o Novo Código Civil. Brasília. 2015. Disponível em: https://www.planalto.gov.br/ccivil_03/_ato2015-2018/2015/lei/ 113105.htm. Acesso em: 12 maio de 2020.

CALLON, Michel. Actor-network theory: the market test. In: LAW, J.; Hassard, J. (Eds.). Actor-Network Theory and after. London: Blackwell, 1999. p. 181-195.

CONCEIÇÃO, Maria Joaquina. A vida quilombola. Capivari do Sul: 2013. No prelo.

CONCEIÇÃO. Maria Joaquina. O pandemônio. Capivari do Sul: 2020. No prelo.

DAUBERMANN, Naíra. Práticas de escrita ordinárias de mulheres negras: memórias e narrativas de si. 322 f. Dissertação (Mestrado em Educação) - Universidade Federal do Rio Grande do Sul, Porto Alegre, 2020 [no prelo].

FERGUSON, James. The anti-politics machine: "development", depoliticization, and bureaucratic power in Lesotho. Cambridge: Cambridge University Press, 1990.

FLEURY, Lorena Cândido; ALMEIDA, Jalcione; PREMEBIDA, Adriano. $O$ ambiente como questão sociológica: conflitos ambientais em perspectiva. Sociologias, ano 16 , v. 35 , p. 34-82, jan.-abr. 2014.

GILROY, Paul. O Atlântico Negro - Modernidade e dupla consciência. Rio de Janeiro: Editora 34; Universidade Cândido Mendes - Centro de Estudos Afro-Asiáticos, 2001.

HARAWAY, Donna. Antropoceno, Capitaloceno, Plantationoceno, Chthuluceno: fazendo parentes. Clima.com, ano 3, n. 5, p. 139-146, 2016.

INCRA - Instituto Nacional de Colonização e Reforma Agrária. Instrução Normativa 57/2009. Regulamenta o procedimento para identificação, quilombos de que tratam o Art. 68 do Ato das Disposições Constitucionais Transitórias da Constituição Federal de 1988 e o Decreto $n^{\circ} 4.887$, de 20 de novembro de 2003. Brasília: INCRA, 2009.

INCRA - Instituto Nacional de Colonização e Reforma Agrária. Relatório Antropológico de Reconhecimento e Delimitação do Território Quilombola da Costa da Lagoa - Capivari do Sul/RS. Porto Alegre: INCRA, 2014.

LATOUR, Bruno. Jamais fomos modernos: ensaio de antropologia simétrica. Rio de Janeiro: Editora 34, 1994.

LATOUR, Bruno. Reagregando o Social: uma introdução à teoria do Ator-Rede. Salvador: EDUFBA; Bauru: EDUSC, 2012.

LATOUR, Bruno. Cogitamus: seis cartas sobre as humanidades científicas. Rio de Janei- 
ro: Editora 34, 2016.

LEITE, Ilka Boaventura. Quilombos e quilombolas: cidadania ou folclorização? Horizontes Antropológicos, n. 10, p. 123-149, 1999.

LEITE, Ilka Boaventura. Laudos Periciais Antropológicos em debate. Florianópolis: NUER; Brasília: ABA, 2005.

LIMA, Roberto Kant de; RABOSSI, Fernando. Entrevista com James Ferguson (Jim) realizada por Fernando Rabossi e Roberto Kant de Lima em Niterói Rio de Janeiro. ANTROPOLÍTICA (UFF), v. 30, p. 173-195, 2011. Disponível em: http://www.revistas. uff.br/index.php/antropolitica/article/view/58/pdf. Acesso em: 16 jun. 2018.

MATTOS, Hebe Maria. Das cores do silêncio: os significados da liberdade no Sudeste escravista, Brasil século XIX. Rio de Janeiro: Nova Fronteira, 1998.

MORAWSKA, Catarina. Vozes da diferença: tempo e transformação entre educadores populares em Pernambuco. Ilha, Florianópolis, v. 19, n. 2, 2017.

O'DWYER, Eliane Cantarino (Org.). Quilombos: identidade étnica e territorialidade. Rio de Janeiro: Editora FGV, 2002.

O'DWYER, Eliane Cantarino. O papel social do antropólogo: a aplicação do fazer antropológico e do conhecimento disciplinar nos debates públicos do Brasil contemporâneo. Rio de Janeiro: E-papers, 2010. (Antropologias, 6).

PAREDES PEÑAFIEL, Adriana Paola. Relações do alimentar e relações que alimentam: El tambo e a Mamacocha no norte do Peru. Tessituras, Pelotas, v. 3, n. 2, p. 219-241, 2015.

RUBERT, Rosane Aparecida. A construção da territorialidade: um estudo sobre comunidades negras rurais da região central do RS. Tese (Doutorado em Desenvolvimento Rural) - Universidade Federal do Rio Grande do Sul - UFRGS, Porto Alegre, 2007.

SLENES, Robert Wayne. Na senzala, uma flor - esperanças e recordações na formação da família escrava: Brasil Sudeste, século XIX. 2. ed. corrigida. Campinas: Editora da Unicamp, 2011.

STENGERS, Isabelle. A proposição cosmopolítica. Revista do Instituto de Estudos Brasileiros, São Paulo, n. 69, p. 442-464, 2018.

STRATHERN, Marilyn. Fora de contexto. São Paulo: Terceiro Nome, 2013.

STRATHERN, Marilyn. O efeito etnográfico e outros ensaios. São Paulo: Cosac Naify, 2014.

TSING, Anna Lowenhaupt. Viver nas ruínas: paisagens e multiespécies no antropoceno.

Brasília: IEB; Mil Folhas, 2019 